\title{
Ecological Civilization Construction for the Saline Industry in Qaidam Basin
}

\author{
Yang Rongjin ${ }^{1}$, Meng Wei ${ }^{1}$, Shu Jianmin ${ }^{1}$, Li Xiuhong ${ }^{2}$, Sun Meiying ${ }^{2}$, Zhang Yi $^{2}$ \\ 1. State Key Laboratory of Environmental Criteria and Risk Assessment, Chinese Research Academy of Environmental Sciences, Beijing 100012, \\ China \\ 2. Beijing Normal University, Beijing 100875, China
}

\begin{abstract}
The saline industry is related to food security in China and is very important for the new energy and new materials industries. Qaidam Basin in Qinghai Province is the center of the saline industry in China. Ecological civilization construction in the saline industry is both important and urgent in this region. This study identifies severe challenges facing ecological civilization construction of the saline industry, based on the present situation in Qaidam Basin. Four strategies are proposed to promote ecological civilization construction of the saline industry and to strengthen the saline industry in Qaidam Basin.
\end{abstract}

Keywords: Qaidam Basin; saline industry; ecological civilization; comprehensive development and utilization; sustainable development

\section{Introduction}

Healthy and orderly development of the Saline industry is of strategic significance to the development of new energy and new materials as well as grain security in China. The types, grades, and reserves of resources in Qaidam Salt Lake, as well as the technology and yield of comprehensive utilization, provide comparative advantages in China. In October 2005, the National Development and Reform Commission and other six ministries and committees listed Qaidam as one of the first batch of 13 pilot industrial parks in China. In March 2010, the State Council formally approved the Overall Planning of the Qaidam Circular Economy Experimental Area in Qinghai. In January 2017, the National Development and Reform Commission issued the 13th Five-Year Plan of Western Development (No. [2017] 89, hereinafter referred to as the "Plan") that was approved by the state council. The Plan requires strengthen- ing the comprehensive utilization of resources of Qaidam Salt Lake; actively promoting new material industries such as aluminum, magnesium, and lithium in Qinghai; and carrying out comprehensive treatment of the ecological environment Qaidam. The ecologically fragile area of the desert oasis in Qaidam Basin, Qinghai, is one of 19 key ecological fragile areas in the country. According to the relevant directive from the central government and combined with the reality of saline industry, the Qinghai provincial government has put forward the strategic layout of " diversifying potassium industry, developing lithium and magnesium industries, integrating alkali industry, and optimizing chlorine industry." Thus, Qaidam Basin should do a good job in the comprehensive development and utilization of saline resources, as well as in the protection of the ecological environment. Therefore, it is necessary and urgent to study the strategy of industrial ecological civilization construction in Qaidam Basin.

Received date: June 16, 2017; Revised date: June 30, 2017

Corresponding author: Meng Wei, State Key Laboratory of Environmental Criteria and Risk Assessment, Chinese Research Academy of Environmental Sciences, Professor; Chinese Academy of Engineering, Academician. Major research field is The Water Pollution Control in River Basin \& Eco-environment Management. E-mail: mengwei@craes.cn

Funding program: CAE Advisory Project "Comprehensive Evaluation and Environmental Coordinated Development of Potassium and New Energy Lithium and Rubidium in Qaidam Salt Lake” (2016-XZ-11); “Strategies of Comprehensive Utilization and Sustainable Development for Saline Lake Resources in Qinghai” (2012ZD-14)

Chinese version: Strategic Study of CAE 2017, 19 (4): 048-053

Cited item: Yang Rongjin et al. Ecological Civilization Construction for the Saline Industry in Qaidam Basin. Strategic Study of CAE, https://doi.org/10.15302/ J-SSCAE-2017.04.008 


\section{Necessity of researching the strategy of saline industrial ecological civilization construction}

In 2013, the Chinese Academy of Engineering launched a major advisory project involving "several strategic studies on the construction of ecological civilization" and conducted an indepth study of industrial ecological civilization [1,2]. In 2012 and 2016, the academy launched a major consulting project, "Strategies of Comprehensive Utilization and Sustainable Development for Saline Lake Resources in Qinghai," and a key advisory project for "Comprehensive Evaluation and Environmental Coordinated Development of Potassium and New Energy Lithium and Rubidium in Qaidam Salt Lake." It conducted continuous research on comprehensive exploitation and development of Qaidam Salt Lake resources, while coordinating with its environment and utilization $[3,4]$.

The construction level of saline industrial ecological civilization has been improving in recent years. However, high-end products of the saline industry have not yet become the mainstream. The circular economy industry system, of which the saline industry is the core, has not yet been established. Nationally, both the technical system and management structure have not yet been able to coordinate effectively. Worldwide, domestic potash fertilizer from saline has played a role in stabilizing the price of imported potash fertilizer. However, the main saline products represented by potash fertilizer and lithium salts still lack enough market influence. Based on the experience of foreign industrial ecology, characteristics of Chinese ecological civilization construction, and comprehensive development and utilization of resources in Qaidam Salt Lake, we suggest that strategic research should be conducted on saline industrial ecological civilization construction. It is of great significance to improve the technical level, industrial characteristics, and management level of the saline industry in China, as well as to improve the competitiveness of the saline lake industries in the market.

\section{Current situation of ecological civilization construction for the saline industry in Qaidam Basin}

The saline industry in Qaidam has experienced both physical and chemical synthesis stages represented by "green salt," "potassium fertilizer," "boric acid," and "pure alkali," It is now entering the stage of barrier separation, barrier adsorption, and electrochemistry, which is represented by "lithium carbonate" and "metal magnesium." The Qaidam saline industry is transforming by ensuring comprehensive development and utilization of resources, high technology, deep processing, and high added value. The lithium industry represented by lithium carbonate has begun to take shape. Moreover, the magnesium industry, represented by metal magnesium, is expected to gradually achieve mass production. The Qaidam saline industry is transforming from a resource-dependent industry into a capital-intensive and high-technology industry (Fig. 1).

The production of green salt has a long history in Qaidam Salt Lake. Since 2007, the production of crude salt in Qaidam was stable at about $2 \times 10^{6} \mathrm{t}$ and was mainly concentrated in the Caka Saline and Keke Saline. From 2010 to 2016, soda ash production increased nearly three times, mainly in the city of Delingha and Da Qaidam industrial park. About $6 \times 10^{5}$ t of caustic soda is produced per year, mainly in Delingha and Qarhan industrial park.

After decades of development, different technology systems such as flotation and crystallization have been utilized in the production of potash fertilizer. Since 2007 , the physical quantity of potash fertilizer increased from $3 \times 10^{6} \mathrm{t}$ to nearly $9 \times 10^{6} \mathrm{t}$, which indicates an increase by nearly two times. The proportion of high-grade potash fertilizer is rising. Apart from potassium chloride, many varieties such as potassium sulfate and potassium magnesium sulfate are also being produced. The capacity for potassium hydroxide, potassium carbonate, and potassium nitrate is being developed.

From 2007 to 2016, the amount of lithium carbonate in Qaidam Basin increased rapidly from $2300 \mathrm{t}$ to about $16000 \mathrm{t}$, and the share of its production was about one-third of the entire country. Qaidam Basin has transformed from only being able produce industrial-grade lithium carbonate to mastering the capacity to scale the production of battery-grade lithium carbonate. The production technology of lithium carbonate in Qaidam Basin mainly includes membrane separation at Qinghai Lithium Co. in East Taijinar Lake, calcining in West Taijinar Lake, and adsorption at Lanke Lithium Co. in Qarhan Saline. The capacity for lithium battery cathode materials, energy storage, and power lithium batteries is being developed.

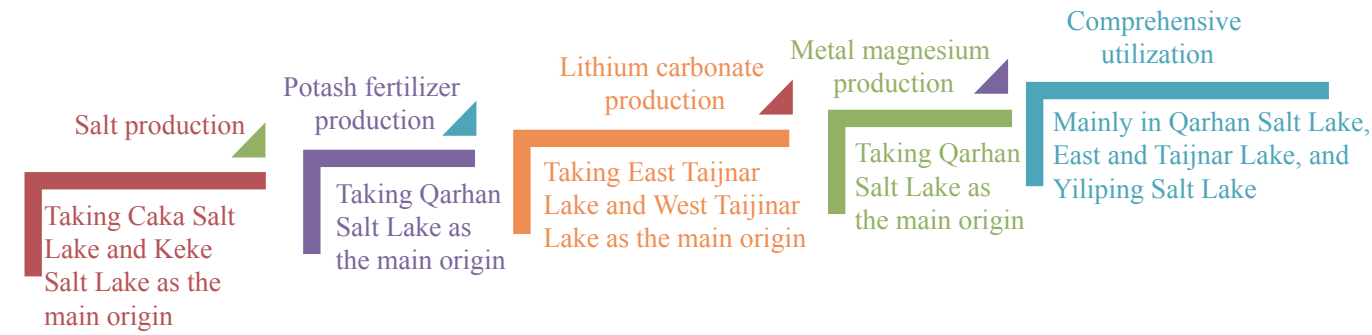

Fig. 1. Development process of the Qaidam saline industry. 
Metal magnesium and its alloys are green engineering materials with the most potential, and they can be applied in the automotive manufacturing, aerospace, metallurgy, and chemical industries. In January 2017, the core device of the magnesium integration project was manufactured successfully in Qinghai Saline Lake Magnesium Industry Co., Ltd., and it could produce $1 \times 10^{5} \mathrm{t}$ metal magnesium annually. Some of the capacity has been built or is being planned, and it covers magnesium alloy ingot, magnesium alloy rolling, metal magnesium, high purity magnesia, magnesium hydroxide, magnesium base, magnesium oxide battery, magnesium thermal storage materials, etc.

Maintaining the "chlorine balance" of the Qaidam Basin is a challenge. Chlorine and hydrogen chloride mainly come from the production processes of magnesium, potassium hydroxide, and caustic soda. Producing polyvinyl chloride (PVC) is the main way to consume chlorine. At present, the production capacity of PVC is about $5.2 \times 10^{5} \mathrm{t}$, and the capacity that is planned and under construction is about $1.44 \times 10^{6} \mathrm{t}$. When sodium chloride is used to produce soda, the chlorine is transferred to the ammonia waste liquid in the form of calcium chloride. In Delingha, ammonia waste liquid is hoisted to a small mountain basin for storage through pipes. This method involves high energy consumption and long-term pollution risk.

\section{Issues and challenges facing the construction of industrial ecological civilization in Qaidam Salt Lake}

The saline industry in China, represented by the Qaidam saline industry, faces several types of issues and challenges in the transformation from "being big" to "being strong." In this way, it can pursue ecological civilization that is in line with not only the world but also Chinese characteristics.

\subsection{Resource inferiority and market weakness}

China is a country relatively lacking in potassium; it has been proven that China's geological reserves of potassium chloride are less than $3 \%$ of the world. More than $90 \%$ of the world's potash reserves are distributed among Russia, Belarus, Canada, and Germany. After years of development and utilization, highgrade potassium resources are seriously inadequate. The ratio of magnesium to lithium in domestic saline is higher than that in most of the saline abroad: this ratio in most of the foreign saline is from 1 to 19 and in the main saline of Qaidam is from 35 to 1825 . After potassium extraction, it is difficult to treat brine using the technical method adopted in foreign saline. Moreover, it is difficult to transform brine into deep saline, which has high magnesium to lithium ratio. Disordered discharge of brine would cause the pollution of intercrystalline brine. The technology for extracting lithium from saline lakes with high magnesium to lithium ratios is difficult to realize and would increase the cost.

China has high dependence on the import of potash fertilizer.
From 2010 to 2016, the amount of imported potassium chloride was maintained at around $5.15 \times 10^{6}-9.4 \times 10^{6} \mathrm{t}$. In 2016 , this amount was $6.82 \times 10^{6} \mathrm{t}$, and the dependence on import reached to more than $40 \%$. Although China has the lowest price of global potash fertilizer, it has not yet obtained control of the negotiating power of the potash market. The advantage of lithium resources in Chinese saline has not yet turned into a market advantage. Chinese recoverable lithium resources account for $27 \%$ of the world's total. The lithium resources in saline account for about one-third of the world, and they are mainly distributed among the Qinghai Qaidam Basin, Tibet Zabuye Saline, and others. In 2016, the output of lithium carbonate from Chinese saline accounted for about $13.6 \%$ of the world output: the output from Qaidam Basin accounted for about 9.1\%. The import dependency ratio of lithium carbonate was over $80 \%$.

\subsection{Shortage of water resources and fragile ecological environment}

The desertification of the Qaidam Basin is one of the most important degradation processes of the ecosystem, and land desertification is closely related to water resources [5]. "Where there is water, there is green. Without water, there is sand." Water resources are the key factors that affect the process of land desertification and maintain ecological stability [6]. The development of water resources has been overloaded in Big Salina, Dalangtan, Delingha District of Bayin River, and Dachaidan Lake. With expansion of the industrial scale, especially of the lithium carbonate and metal magnesium industries, water demand will increase sharply. In 2020, the development and utilization of water resources will be overloaded or face a large risk of being overloaded in Golmud area, Mohair area of Iqe River Basin, and the water system of Xiaochaidan Lake.

Qaidam Basin is fragile with limited environmental bearing capacity. The exploitation and utilization of Qaidam saline resources have caused ecological environment damage [7]. With the expansion of the saline industrial scale and increase in product types, the species and quantity of pollutants, as well as the pressure of ecological environmental protection, will continue to increase. Projects such as Qaidam Salt Lake's comprehensive utilization of resources in the first and second phases; integration of magnesium metal, lithium carbonate, soda ash, and caustic soda; and others have been built and put into operation. This has increased the pressure of dealing with brine after potassium extraction, ammonia waste liquid, chlorine gas, and hydrogen chloride. Capacity of the saline and the river in Qaidam is limited, and the carrying capacity of the water environment is insufficient.

\subsection{Development of resources with insufficient protection of reserves}

There are little high-grade potassium and boron resources left 
in Qaidam Basin. At present, Qaidam is mainly concentrating on the development of middle- and low-grade potassium and boron resources. The development and utilization of saline resources lacks systematic and comprehensive protection planning. In this process, there are several behaviors that seriously damage the mining resources of saline, such as mining resource rich areas, abandoning the poor, and mining too much and too fast. Disordered discharge of brine after potassium extraction also causes the pollution of intercrystalline bittern. The overall development model of saline resources has become redundant and focuses on the increase in product quantity. Potassium resources are strategic materials to ensure the security of national agriculture and food. Lithium resources are future strategic competitive materials as regards new energy and new materials. For both these resources, an effective national strategic reserve system for saline lake resources has not been set up to cope with the changes in the international market and ensure the security of the country. It is necessary to effectively build a key saline resources reserve system by using the strategic repository and strategic reserve mechanism of saline as the core and making full use of the "two kinds of resources" and "two markets" at home and abroad.

\subsection{Technology is isolated and lack of innovation guidance}

There are many technical routes for producing potassium chloride, lithium carbonate, and other main saline products in Qaidam Basin [8]. It is obvious that each enterprise develops the technology in its own way. The Qinghai Provincial Science and Technology Department has tackled the key technical links with its major scientific and technological projects. Various industrial innovation alliances, such as for lithium, have strengthened technical information communication among enterprises. However, not enough attention has been paid to comparison of the different technical routes and selection of the most suitable route based on the saline characteristics.

At present, innovations as regards the resources and regional characteristics of saline are still insufficient. Although breakthroughs have been made in the technology for producing some saline products, in view of the symbiotic characteristics of Qaidam saline resources, there is a lack of systematic, comprehensive, and forward-looking exploration for their comprehensive development, utilization, and protection. Some progress has been made for saving energy and water in the saline industry. However, there has not yet been leading progress in the seamless connection of the solar photovoltaic and saline industries, as well as in the design of water-saving technology for saline products.

\subsection{Difficulty in meeting the demand for middle and high level talent, and the management system's lack of smoothness}

Comprehensive development and utilization of Qaidam saline resources increase the demand for high-level talent with different specialties and various skilled technicians. Many production lines of middle and high-end saline products is under planning, construction, and commission, such as for metal magnesium and battery-grade lithium carbonate. Moreover, the project for comprehensive exploitation and utilization of saline resources is being promoted. Therefore, the demand gap between middle and high level talent is becoming increasingly larger. The time required for local cultivation of professional and technical personnel is quite long, making it difficult to meet the urgent talent needs by relying on local training. It is difficult to introduce and retain high-level talent from middle and eastern China, and a large number of excellent local talents from Qinghai and Qaidam Basin have been outflowing.

In May 1999, the Salt Lake Administration Bureau of the Qinghai Provincial Department of Land and Resources and the Golmud Qarhan Salt Lake Administration were established. With two tiles of a team, the administration is mainly under the leadership of the Golmud Government. According to the work report of the Saline Administration Bureau in 2016, the administration mainly concentrates on the supervision and management of mineral resources and the collection of compensation fee for mineral resources in the Salt Lake The administrative level of the administration is low. From the perspective of national food security and saline strategic resource security, the demand for establishing a trans-provincial (autonomous region) saline management institution centered on Qaidam Basin is becoming increasingly urgent. This could address the issues of the planning and layout of saline resources, market price negotiation of main saline products, protection of the strategic saline resources, and the reserve of saline products.

\section{Construction strategy of industrial ecological civilization in Qaidam Salt Lake}

The study on strategies for the construction of saline industrial ecological civilization should also consider domestic and international resources, products, market, technology, management reality, and characteristics of the resources and environment in Qaidam Basin. Putting forward these strategies would be helpful to improve the ecological civilization level of the saline industry, realize the comprehensive development and utilization of saline resources, and ensure sustainable development of the regional social economy.

\subsection{Top stratagem planning and macro-management strategy}

The top stratagem plan and design for utilizing and exploiting saline resources should be strengthened. It is proposed to take the planning of comprehensive exploitation and utilization of Qaidam saline resources as the core and compile the national 
strategic plan for comprehensive exploitation and utilization of saline resources to promote the formation of the "big saline industry" system. Comprehensive utilization of saline resources includes not only saline mining $[9,10]$ but also saline agriculture $[11,12]$. Saline mining is represented by the exploitation of potassium, lithium, boron, sodium, magnesium, and other saline resources. Saline agriculture is represented by the exploitation and utilization of saline biological resources and the salt tolerance of biological resources around the saline. In addition, the saline tourism services industry is also included, which is represented by saline sightseeing, saline health care, and publicity of the salt lake (such as the Salt Lake Museum in Qinghai and the "Sky No. 1" scenic spot in Caka Salt Lake). Moreover, the national strategic plan for comprehensive exploitation and utilization of saline resources should also consider the Belt and Road Initiative, the 13th Five-Year Plan of Western Development, and the 13th Five-Year Plan of Mineral Resources. The resource distribution, development, and utilization areas of key salt lakes in foreign countries should be considered, as well as the production, market supply, and demand of main saline products and saline enterprises, to promote the formation of the international and domestic pattern of "two kinds of resources" and "two markets." To promote the application of solar photovoltaic power in the saline industry and the energy storage technology of molten salt, the related coupling between the saline industry and industries such as energy and metallurgy should be strengthened. The connection between the petrochemical, natural gas, chemical, and saline chemical industries should be strengthened to realize the "chlorine balance." The coupling between the saline and metallurgical industries should also be strengthened. Making full use of sulfuric acid from the metallurgical industry as the raw material for the saline industry as well as strengthening the combination of magnesium, lithium, sodium, and other saline metal products with aluminum, lead, zinc, and manganese in the field of alloys would promote the development of new and functional materials. The strategic plan for the comprehensive exploitation and utilization of saline resources should focus on resolving the following issues: sustainably developing strategic reserves of potassium resources; stabilizing the price of potash fertilizer globally; defending food security in China; researching and developing low cost, low consumption, and environmentally friendly lithium carbonate production equipment and technology with high magnesium to lithium ratio; utilizing domestic lithium resources to reduce import of lithium products [13]; integrating brine after extraction of potassium and metal magnesium; and comprehensively utilizing ammonia waste liquid and calcium chloride to ensure a "chlorine equilibrium" [14].

There should be innovations in the management mechanism and improvement in the macro-management level of saline. To increase the administrative level and management authority of the Saline Administration Bureau, it is necessary to establish a national management organization for the comprehensive ex- ploitation and utilization of saline resources at the national level. The Qinghai Saline Administration Bureau should be set up to manage the Qinghai Saline resources comprehensively. The National Development and Reform Commission should set up the National Saline Resource Comprehensive Utilization Office for unified planning and management of national saline lake resources and for carrying out price negotiations on the bulk of saline lake products on behalf of China, among other responsibilities. Tax, credit, and other management tools could be used to promote the ecological transformation of the saline lake industry. This could improve the industry's macro-management level and address issues such as resource wastage and low efficiency, which might be caused by disordered competition, information opacity, and the unopen technology of saline lake enterprises.

\subsection{Strategy for prioritization of resources and ecological protection}

We suggest implementing the strategy for prioritization of resources and ecological protection. According to the distribution characteristics, details of the exploitation and utilization of potassium and solid potassium resources at home and abroad should be compiled for the near, middle, and long terms. It is proposed to delimit the exploitation and utilization redline of potassium resources, control the intensity of exploiting and utilizing potassium resources, keep increasing the yield of potassium salt, develop and utilize low grade potash ore, strengthen the exploration of potassium resources that include underground brines, and establish a strategic reserve storehouse and reserve mechanism for potassium resources.

In the key development area of saline resources, first, the strategy of protecting water resources should be implemented. The "three red lines" of water resource management should be strictly enforced in the Haixi Mongol and Tibetan Autonomous Prefecture, where Salt Lakes located. Thus, it is necessary to study ways to establish the red lines of water resource management for basins that are the key development areas of saline resources, as well as to study the quota of the total amount of water for the saline industry, requirement of water efficiency, and other indexes. Water resource demand for comprehensively exploiting and utilizing saline resources should be especially examined in Qarhan Saline, East Taijnar Lake, West Taijnar Lake, and Yili Ping Saline. Moreover, monitoring and management of water resource should be strengthened.

We suggest implementing the strategy of protecting the ecology first. Both ecological water demand and the ecological basin process of important rivers, lakes, wetlands, and salinized meadow vegetation should be studied in depth, and the former should be protected first. The safety of oases, rivers, lakes, and wetlands should be maintained. Ecological degradation of salt marsh and halophyte desert in the low plain soil zone should be avoided. The protection work should be strengthened, particularly in the 
downstream of Bayinguole River, Golmud River, Yuka River, Tataling River, and Nalingguole River.

\subsection{Strategy for comprehensive development and utilization of saline resources and for development of a circular economy}

We suggest implementing the strategy of comprehensively exploiting and utilizing saline resources. Making full use of the symbiotic characteristics of various saline resources in Qaidam Basin and based on the first and second stages of the project for comprehensively utilizing saline resources, the government should strive toward comprehensive development and utilization of the resource base, which comprises the Qarhan Saline, East Taijnar Lake, West Taijnar Lake, and Yiliping Saline. Qarhan Saline is rich in the storage of brine after potassium extraction. It is a suitable comprehensive development and utilization base for potassium, lithium, boron, and chlorine resources, for which the integration of metal and magnesium is considered a breakthrough. The western saline resources' comprehensive development and utilization base has good lithium resources, and it is a good lithium industry base. It is suitable for developing the comprehensive utilization base of potassium and boron resources, for which lithium carbonate and lithium batteries are considered a breakthrough. Therefore, the technology of comprehensive exploitation and utilization of saline lake resources should be actively developed. It is proposed to make full use of the "Belt and Road" opportunity, and to apply the technology for comprehensive development and utilization of saline resources to other domestic saline lake resources concentrated in the distribution area, in the enrichment area of saline resources in countries along the "Belt and Road," and in other countries.

We suggest establishing a circular economy industrial system strategy based on the exploitation and utilization of saline resources. Qaidam Salt Lake has abundant resources of coal, oil, natural gas, limestone, etc., and it is suitable for developing the industrial system of the circular economy. It is proposed to make full use of brine after potassium extraction, ammonia waste liquid, chlorine gas and hydrogen chloride, dilute hydrochloric acid, sulfuric acid, etc.; develop metal magnesium, calcium chloride, PVC, and other related industries; reduce the cost of pollutant discharge and pollutant disposal; extend the industrial chain; and increase the added value of the product. In addition, it is proposed to make full use of the related funds and policies of Qaidam circular economy experimental area, break through the bottleneck of comprehensive development and utilization of saline resources, and build a resource-saving and environment-friendly circular economy industrial technology system. It is proposed to actively develop green products and technologies with low energy consumption, low water consumption, low pollution and emission, high purity, and added value. A national standard system for cleaner saline lake industrial production should be studied and established.
5.4 Strategy for talent introduction and cultivation and for driving of scientific and technological innovation

We suggest implementing the strategy of introducing nonlocal talent and training local talent. The implementation of a diversified and flexible talent introduction project should make full use of the Western doctoral service group, mechanism of the counterpart assistant Qinghai, industrial technology innovation alliance, Qaidam Circular Economy Research Institute, entrepreneurial post-doctoral workstations, scientific and technological project bidding or joint research, academician workstations, expert consultation group, etc. This will solve issues related to high- and mid-level talent research, spousal employment, children's education, and others. It is proposed to strengthen cooperation with colleges, universities, higher vocational schools, and secondary vocational schools in the inland; cultivate high-quality labor that can meet the demand of developing the saline; and carry out joint education and training. The environment of talent development should be optimized to retain excellent local professional and technical personnel and reduce the outflow of talent.

We suggest implementing the driving strategy of scientific and technological innovation, and breaking through the bottleneck of the key technology of comprehensive utilization. We advise that the country should keep increasing the investment in scientific and technological research and development for the comprehensive exploitation and utilization of saline resources. China should guide the research and development of saline resources to be collected in the Qaidam Basin. Facing the key technical issue of exploitation and utilization of saline resources, such as potassium, lithium, magnesium, sodium, chlorine, and boron, the government should set up a major, special national research and development plan for saline resources' comprehensive development and utilization, and organize research institutes and key enterprises to carry out centralized joint efforts. Qinghai and Qaidam's circular economy experimental areas should speed up their core technology research by setting up the saline high-level talent or team introduction project, saline major science and technology special project, key technology research and development project, and so on. As regards equipment, technology, and other issues in exploiting and utilizing saline resources, key saline enterprises should promote equipment improvement and technological innovation by establishing a post-doctoral workstation, sending technicians to other places for cultivation, and organizing joint research by consulting expert teams and research institutes.

\section{Conclusions}

The construction of Qaidam Salt Lake industrial ecological civilization is the inevitable choice for the comprehensive utilization and exploitation of saline resources in China. It is the 
only route by which the Chinese saline industry can participate in global competition and transform from "being big" to "being strong." To implement the General Plan of the Qaidam Circular Economic Experimental Area in Qinghai Province that was approved by the State Council in 2010, as well as the general request of general-secretary Xi Jinping in 2016 for the comprehensive development and utilization of saline resources, it is necessary to face the difficulties in constructing an industrial civilization in Qaidam Salt Lake. It is proposed to seize the opportunity of implementing the national ecological civilization construction strategy, the Belt and Road Initiative, and 13th FiveYear Plan of Western Development in order to break through the bottleneck for comprehensively utilizing and exploiting saline resources, as well as innovate the capital, technology, talent, and monitoring and management system to adapt to the saline industrial ecological civilization construction [15]. This would help form the system of the "big saline industry," which is not only in line with the development of the international saline industry but also has the industrial characteristics of China and Qaidam Basin. To ensure the sustainable and healthy development of the saline industry in China, and Qaidam in particular, it is necessary to set up a high-level saline industrial management organization to improve the management's effectiveness. By establishing a major scientific and technological project for comprehensively exploiting and utilizing saline resources, the key theoretical and technical issues would be solved, thus leading to continuous improvement of the influence and negotiating power of China in the field of the saline industry.

\section{References}

[1] The Comprehensive Research Group for Research on Several Strategic Issues of Ecological Civilization Construction. Research on several strategic issues on ecological civilization construction [J]. Strategic Study of CAE, 2015, 17(8): 1-7. Chinese.

[2] Fu Z H, Song Z K, Chen X H, et al. Study on green development strategies for the industry in China [J]. Strategic Study of CAE, 2015, 17(8): 16-22. Chinese.
[3] Meng W, Shu J M, Yang R J, et al. Development and utilization of saline lake resources and protection of ecological environment in Qaidam Basin in Qinghai Province [J]. Acta Geologica Sinica(English Edition), 2014, 88(s1): 191-193.

[4] Yang R J, Li Y W, Tian H Y. Analysis and countermeasure study on environmental impact of lithium resources development in Qinghai saline lake [J]. Environment and Sustainable Development, 2014, 39(2): 91-94. Chinese.

[5] Guo Y W, Zhang H F, Xiao J Y, et al. Ecological protection and suggestions are fundamental to the development of the Qaidam [J]. Journal of Arid Land Resources and Environment, 2000, 14(4): 11-15. Chinese.

[6] Liu Y H. The rational use of water resources and ecological environment protection $[\mathrm{M}]$. Beijing: China Science Publishing \& Media Ltd., 2000. Chinese.

[7] Zheng M P. Salt lake resources and ecological environment in China [J]. Acta Geologica Sinica, 2010, 84(11): 1613-1622. Chinese.

[8] Zheng M P, Zhang Y S, Liu X F, et al. Progress and prospects of salt lake research in China [J]. Acta Geologica Sinica, 2016, 90(9):2124-2165. Chinese.

[9] Song P S, Li W, Sun B, et al. Recent development on comprehensive utilization of salt lake resources [J]. Chinese Journal of Inorganic Chemistry, 2011, 27(5): 801-815. Chinese.

[10] Zheng M P, Bu L Z. Rational development and comprehensive utilization of salt lakes resources [J]. Conservation and Utilization of Mineral Resources, 2009(1): 17-22. Chinese.

[11] Zheng M P. The view of "saline lake agriculture" [J]. Journal of Earth, 1995, 16(4): 404-418. Chinese.

[12] Zheng M P. Saline lake agriculture and saline alkali agriculture [J] Science \& Technology Review, 2014, 32(35): 1. Chinese.

[13] Wu R X. The exploitation and utilization of lithium resources and $\mathrm{Li}_{2} \mathrm{CO}_{3}$ Industry [J]. Materials Review, 2012, 26(9): 36-39, 48. Chinese.

[14] Zhang X J, Wu P T, Zhang Z C, et al. Analysis on the transformation and conversion of chlorine element in Qaidam circular economy pilot area $[\mathrm{J}]$. Journal of Hebei University of Science and Technology, 2014, 35(5): 460-465. Chinese.

[15] Wang J P, Ling Z Y, Chen L, et al. Design and implementation of an integrated monitoring and pre-warning system of salt lake resources based on multi-source information fusion theory [J]. Journal of Salt Lake Research, 2016, 24(1): 50-57. Chinese. 